\title{
Leadership Competencies of Tennessee Extension Agents: Implications for Professional Development
}

\author{
John L. Hall \\ Assistant Professor \\ Tennessee State University \\ Nashville, TN 37209 \\ Thomas W. Broyles \\ Associate Professor \\ Tennessee State University \\ Nashville, TN 37209
}

\begin{abstract}
The study's purpose was to determine Extension agents' $(n=111)$ perceived level of importance, knowledge, and training needs for leadership skills. Mean Weighted Discrepancy Scores were calculated to determine training needs. Participants' perceived responses were average to above average importance for all skills; however, the participants' perceived responses were varied concerning knowledge for most skills. The five highest rated training needs were resolve conflict, efficiently manage time, assess community needs, effectively lead a team, and prioritize tasks. The only common training need by Agriculture \& Natural Resources (ANR), Family \& Consumer Sciences (FCS), and 4-H agents was resolve conflict. Create vision was a training need only identified by FCS agents. The 4-H role needs were handle emotions and handle criticism.
\end{abstract}

\section{Introduction/Literature Review}

Cooperative Extension agents are the critical link between higher education institutions and stakeholders in the community. Extension agents spend their career sharing knowledge and experiences to build stronger communities. However, content cannot be the only focus, according to Anderson (2013), "leadership is the most important ingredient to building a strong community (para. 1). Extension agents must employ effective leadership skills and practices while delivering content knowledge and experience.

The role of an Extension agent through the lens of volunteer management, teaching needs, serving as a counselor, and countless other roles has been examined for decades (Boyd, 2004; Gallaher \& Santopolo, 1967; George, 1968; Patton \& Blaine, 2001; Robinson, 1964; Trent $\&$ Donohue, 1971). The focus of the aforementioned studies range from program content to which audiences should be served. According to Moore and Rudd (2005), most employers would agree that leadership skills are desirable in employees regardless of the specific job roles they must perform. From state to state and county to county, program content details and the audiences served may vary; however, one role that all agents have in common is teacher/leader. 
Cooper and Graham (2001) stated, "The first county agents were itinerant teachers" (para.1). Townsend (1999) said "Teaching is an enormous responsibility where teachers are leaders" (p. 4). And John F. Kennedy believed "leadership and learning are indispensable to each other" (John F. Kennedy Presidential Library \& Museum, n.d. para.3). The content and audiences served by Extension agents may vary, but the need and expectation to teach/lead is evident in every community.

Skills Needed to Effectively Lead. Numerous studies examining competencies needed for Extension agents to be successful have been conducted (Boyd, 2004; Cooper \& Graham, 2001; Gonzalez, Howell, \& Lindley, 1984; Lakai, 2010; McClure, Fuhrman, \& Morgan, 2012; McKim, Lawver, Enns, Smith, \& Aschenbrener, 2013). However, research examining the leadership needs and abilities of extension personnel is limited. Moore and Rudd (2004 \& 2005) studied the leadership skill areas of extension administrators, but there is not a single study focusing specifically on the leadership needs and abilities of Extension agents.

A case for the inextricable connection between agents and the need to teach and lead has been identified. Therefore, examining the question "What leadership skills can agents develop to become more effective leaders?" is appropriate. No matter how many different roles a county agent plays, leading is always at the core of what they do. People come to agents seeking answers to the problems and challenges they face. In order to be an effective Extension agent, one must also have the necessary leadership skills that enable him/her to carry out the various aspects of the job. A conceptual framework to understand what is meant by "skill" is important. In a Harvard Business Review article, Katz (1955) defined skill as "an ability which can be developed, not necessarily inborn, and which is manifested in performance, not merely in potential" (pp. 33-34).

Katz (1955) suggested that leadership is dependent upon three basic skills: technical, human, and conceptual. Technical skills would be considered those needed to perform in a specialized area that requires specific tools and techniques. Human skills are those needed to effectively work with people. Conceptual skills are needed to generate and articulate ideas in an organization related to visioning and strategic planning.

\section{The Leadership Context}

In addition to examining important leadership skills needed by Extension agents, it is also important to note the context(s) in which the agents lead. The researchers will provide insight into the Cooperative Extension Service to highlight the vital role that Extension plays at the national, state, and local levels. Failure to recognize the culture and climate of Extension would create a disconnect between leadership theory and practice. Andenoro et al. (2013) stated, "it is critical to consider the content and the leaner within the Leadership Education context" (p.12).

The structure of the Cooperative Extension Service provides trained professionals and resources to help reach the desired outcome set by Andenoro et al. (2013) for the "Development of Vibrant \& Resilient Communities" (p.22). A primary function of the Extension Service is to provide knowledge and resources generated by the teaching and research experts at land-grant universities to individuals in communities across the state and country. According to Woodrum 
and Safrit (2003), it is important "to attract Extension agents who are leaders and can create and share a vision of community based educational programming into the $21^{\text {st }}$ century" (para. 3 ). To ensure agents have the leadership skills to positively impact their communities, "it will be critical for leadership scholars and educators to create research lines that will address the development of these communities" (Andenoro et al., 2013 p.22).

State Cooperative Extension budgets are tight and Extension administrators are looking for ways to compensate for reductions in funding (McClure, Fuhrman, \& Morgan, 2012); therefore, efficiently utilizing resources (specialists' and agents' time, travel expenses, training materials, etc.) for professional development activities is imperative. Extension agents are responsible for the day-to-day activities aimed at increasing knowledge of agriculture among the general public. The professional development opportunities available to agents should equip them to best serve these needs. Information collected from Extension agents through a needs assessment will allow Extension specialists to create timely and relevant in-service trainings.

According to Andenoro et al., "Communities are facing considerable challenges and complexity" (2013 p.22). Extension agents are in an ideal position to address the "complex problems and challenges faced by local communities today" (Doerfert, 2011 p. 28). However, in order to adequately handle such issues, "we must be able to better understand the models, strategies, and tactics needed to best prepare, promote, and retain new professionals who demonstrate the requisite content knowledge, technical competence, and cultural awareness, coupled with communication and interpersonal skills" (Doerfert, 2011 p.20). Studies examining the needs of Extension agents can help inform the profession and allow for tailored professional development opportunities that support the agents' needs.

Research that identifies the leadership needs and abilities of Extension agents is a critical tool that will assist agents in developing the leadership skills they need to effectively perform their various roles. This research study fills a void in the literature and provides valuable information that will be used to create relevant and practical professional leadership development curricula and trainings for Extension agents. This study aligns with the National Leadership Education Research Agenda. Andenoro et al. (2013) identified several key priority areas that should be addressed to advance the profession. Through this study the researchers sought to contribute to the key priority areas by examining aspects of Priority Two: Programmatic Assessment and Evaluation and the concept of being "more adept at understanding how to empower the development of those we serve" (p. 9). In addition, Priority Six: Social Change and Community Development address the need for learners "to understand themselves and the change they wish to enable" (p. 22). Extension agents must understand their own leadership needs, how to grow and develop based on their leadership needs, and be able to apply leadership knowledge and skills with stakeholders in the community.

\section{Purpose and Objectives}

The purpose of this study was to determine the leadership-related competencies of Extension agents in Tennessee according to the essential competencies identified in the literature. Borich's (1980) needs assessment model was used to prioritize the competencies by importance to the agents' knowledge of each competency. The following objectives guided the study: 
1. Describe the demographic characteristics of participants.

2. Describe the importance and knowledge of activities within seven leadership categories as perceived by Tennessee Extension agents.

3. Determine the leadership competency areas that have the greatest need for professional development (high priority areas).

4. Determine whether the high priority leadership competency areas vary with Extension agents' program area.

\section{Procedures}

The researchers performed a comprehensive review of the literature on leadership-related competencies within the context of Extension (Boyd, 2004; Cooper \& Graham, 2001; Moore \& Rudd, 2004). Forty-seven (47) competencies were found to be most critical as agreed upon by an expert panel. Competencies were grouped into the following seven categories/constructs with the associated number of items/skills comprising each construct in parentheses: communication (4 skills), developing leaders (6 skills), management (8 skills), personal development (10 skills), strategic/planning (8 skills) teamwork (6 skills), and volunteer (5 skills).

The questionnaire was created using Qualtrics and shared with an expert panel to examine the instrument for face and content validity. The expert panel suggestions included clarifying the wording of a few competencies and adding two additional questions about the agents' previous leadership experience. The suggestions of the expert panel were taken into account and the instrument was revised. The revised instrument was electronically sent to the randomly selected Extension agents in Tennessee $(n=111)$ via Qualtrics. The randomly selected Extension professionals were asked to respond to basic demographic and descriptive questions. The Tailored Design Method was followed (Dillman, Smyth, \& Christian, 2009). Eighty-six agents responded (77\% response rate). There were 69 completed instruments in entirety and no significant differences were found between early and late responders (Lindner, Murphy, \& Briers, 2001).

The researchers investigated the level of importance for selected leadership skills. The Likert scale used for importance of the skill was 1=No Importance, 2=Below Average Importance, 3=Average Importance, 4=Above Average Importance, 5=Utmost Importance. Cronbach's alpha $(\alpha=0.96)$ was calculated for the importance scale. In addition to the importance scale, the researchers investigated the level of knowledge for selected leadership skills. The Likert scale used for knowledge of the skill was $1=$ No Knowledge, $2=$ Below Average, 3=Average Knowledge, 4=Above Average, 5=Exceptional Knowledge. Cronbach's alpha $(\alpha=0.96)$ was calculated for the knowledge scale.

The data were collected using Qualtrics and imported into PASW Statistics 18.0 ${ }^{\mathrm{TM}}$. Means and standard deviations were calculated for participants' perceived importance and knowledge of the leadership skills. In addition, Mean Weighted Discrepancy Scores were calculated to determine training needs. Mean Weighted Discrepancy Scores were calculated first by determining the Discrepancy Score (DS). The DS score was calculated by subtracting the knowledge score from the importance score. The next calculation was to determine the Weighted Discrepancy Score (WDS). The WDS was calculated by multiplying the DS by the 
mean of the importance rating for each skill. The last step was to calculate the Mean Weighted Discrepancy Score (MWDS). Summing the WDS and dividing by the number of responses for each skill calculated the MWDS (see Figure 1).

$$
\begin{gathered}
\text { DS = Importance Rating }- \text { Knowledge Rating } \\
\text { WDS }=\text { DS x Mean Importance Rating } \\
\text { MWDS }=\Sigma \text { WDS } / n
\end{gathered}
$$

Figure 1. Formulas used to calculate MWDS.

\section{Findings}

The participants in the research were predominantly female (59.4\%) and mostly 4-H agents (see Table 1). There was even representation of early and mid-career agents and aheavier emphasis on veteran agents $(47.8 \%)$ with over 16 years of experience. Seventy-two percent of the participants had a Master's degree.

\section{Table 1.}

Participant Demographics

\begin{tabular}{llcc}
\hline Characteristics & & $f$ & $\%$ \\
\hline Gender & Male & 28 & 40.6 \\
& Female & 41 & 59.4 \\
Role & ANR $^{\mathrm{a}}$ & 24 & 34.8 \\
& $\mathrm{FCS}^{\mathrm{b}}$ & 17 & 24.6 \\
& $4-\mathrm{H}^{\mathrm{c}}$ & 28 & 40.6 \\
Years of Experience & 1 to 5 years & 18 & 26.1 \\
& 6 to 10 years & 7 & 10.1 \\
& 11 to15 years & 11 & 15.9 \\
& 16 to 20 years & 14 & 20.3 \\
& 21 to 25 years & 5 & 7.2 \\
& 26 to 30 years & 7 & 10.1 \\
& More than 30 years & 7 & 10.1 \\
Highest Degrees Earned & Bachelor's & 18 & 26.1 \\
& Master's & 50 & 72.5 \\
& Doctorate & 1 & 1.4 \\
\hline
\end{tabular}

Notes. ${ }^{a}$ Agriculture and Natural Resources. ${ }^{b}$ Family and Consumer Sciences. ${ }^{c} 4-\mathrm{H}$.

The participants' perceived responses were average to above average importance for all skills. According to Table 2, the participants responded that the five most important skills were demonstrate appropriate behavior $(\mathrm{M}=4.68, \mathrm{SD}=0.52)$, exhibit honesty $(\mathrm{M}=4.66, \mathrm{SD}=0.56$, exhibit positive attitude $(\mathrm{M}=4.59, \mathrm{SD}=0.50)$, model integrity $(\mathrm{M}=4.59, \mathrm{SD}=0.60)$, and build relationships with community $(\mathrm{M}=4.58, \mathrm{SD}=0.58)$. The five least important skills were show empathy $(\mathrm{M}=3.94, \mathrm{SD}=0.71)$, plan strategically $(\mathrm{M}=3.87, \mathrm{SD}=0.77)$, negotiate $(\mathrm{M}=3.81$, $\mathrm{SD}=0.75)$, show courage $(\mathrm{M}=3.81, \mathrm{SD}=0.81)$, and serve as a coach $(\mathrm{M}=3.80, \mathrm{SD}=0.75)$. 
Table 2.

Extension Agents' Perceived Level of Importance of Leadership $\quad M \quad S D$ Skills.Statement

Demonstrate Appropriate Behavior

Exhibit Honesty

Exhibit a Positive Attitude

Model Integrity

Build Relationships with Community

Resolve Conflict

$4.68+.52$

Prioritize Tasks

$\begin{array}{ll}4.68 & .52 \\ 4.66 & .56\end{array}$

Efficiently Manage Time

$4.59 \quad .50$

Exhibit Accountability

Model Respectful Behavior

4.59

.50

Employ Listening Skills

$\begin{array}{ll}4.58 & .58\end{array}$

Assess Community Needs

$4.54 \quad .58$

Effectively Lead a Team

$4.51 \quad .58$

Communicate through Public Speaking

$4.51 \quad .63$

Effectively Contribute to the Team

4.49

.65

Set Goals

Desire to Learn New Knowledge

4.49

.68

Achieve Goals

4.43

.65

Employ Problem Solving Skills

4.41

.69

Build Relationships with Peers

4.39

.62

4.38

.77

4.37

.64

4.36

.68

4.36

.70

Handle Emotions

4.34

.74

Develop Managerial Skills

Display Enthusiasm

4.30

.65

Reading Skills

4.30

.71

Delegate Tasks

4.27

.79

Demonstrate Creative Thinking

4.26

.62

4.25

.65

Handle Criticism

$4.24-.79$
.4 .23

Exhibit a Sense of Humor

4.23

.64

Create Stability

Produce professional written documents

4.19

.69

Create Vision

4.18

.68

Openness to Organizational Change

4.17

.68

Recognize Volunteers

$4.15 \quad .68$

$4.13 \quad .73$

Develop Volunteers

$4.13 \quad .66$

Recruit Volunteers

Engage in Critical Thinking

$4.13 \quad .74$

Serve as a Mentor

4.12

.76

$4.09 \quad .72$

Manage Volunteers

4.08

.66

Promote Cultural Awareness/Diversity

4.07

.71

Evaluate People

$4.06 \quad .78$

$4.04 \quad .79$

Train Volunteers

$4.04 \quad .85$

Identify Talent

$4.01 \quad .75$

Show Empathy

Plan Strategically

3.97

.77

$3.97 \quad .80$

Negotiate

3.94

.71

$\begin{array}{ll}3.87 & .77\end{array}$

Show Courage

3.81

.75

Serve as a Coach

3.81

3.80

.81

Note. Importance Scale: 1=No Importance, 2=Below Average Importance, 3=Average Importance, 4=Above Average Importance, 5=Utmost Importance. 
The participants' perceived responses were varied concerning knowledge for most skills. According to Table 3, the participants responded that the five most knowledgeable skills were exhibit honesty $(\mathrm{M}=4.21, \mathrm{SD}=0.75)$, demonstrate appropriate behavior $(\mathrm{M}=4.18, \mathrm{SD}=0.67$, model integrity $(\mathrm{M}=4.07, \mathrm{SD}=0.70)$, model respectful behavior $(\mathrm{M}=4.06, \mathrm{SD}=0.68)$, and reading skill $(\mathrm{M}=4.01, \mathrm{SD}=0.81)$. The five least knowledgeable skills were develop volunteers $(\mathrm{M}=3.28, \mathrm{SD}=0.80)$, recruit volunteers $(\mathrm{M}=3.26, \mathrm{SD}=0.83)$, train volunteers $(\mathrm{M}$ $=3.23, \mathrm{SD}=0.83)$, manage volunteers $(\mathrm{M}=3.22, \mathrm{SD}=0.80)$, and plan strategically $(\mathrm{M}=3.20$, $\mathrm{SD}=0.76)$ 


\begin{tabular}{|c|c|c|}
\hline $\begin{array}{l}\text { Table 3.Extension Agents' Perceived Level of Knowledge of } \\
\text { Leadership Skills. Statement }\end{array}$ & $M$ & $S D$ \\
\hline Exhibit Honesty & 4.21 & .75 \\
\hline Demonstrate Appropriate Behavior & 4.18 & .67 \\
\hline Model Integrity & 4.07 & .70 \\
\hline Model Respectful Behavior & 4.06 & .68 \\
\hline Exhibit a Positive Attitude & 4.04 & .59 \\
\hline Reading Skills & 4.01 & .81 \\
\hline Exhibit Accountability & 3.97 & .70 \\
\hline Display Enthusiasm & 3.93 & .76 \\
\hline Desire to Learn New Knowledge & 3.92 & .80 \\
\hline Exhibit a Sense of Humor & 3.92 & .71 \\
\hline Build Relationships with Peers & 3.86 & .75 \\
\hline Effectively Contribute to the Team & 3.82 & .68 \\
\hline Build Relationships with Community & 3.80 & .78 \\
\hline Employ Listening Skills & 3.78 & .76 \\
\hline Communicate through Public Speaking & 3.78 & .82 \\
\hline Achieve Goals & 3.73 & .78 \\
\hline Set Goals & 3.71 & .73 \\
\hline Employ Problem Solving Skills & 3.69 & .84 \\
\hline Prioritize Tasks & 3.68 & .81 \\
\hline Serve as a Mentor & 3.63 & .77 \\
\hline Produce professional written documents & 3.61 & .91 \\
\hline Show Empathy & 3.57 & .72 \\
\hline Openness to Organizational Change & 3.57 & .73 \\
\hline Efficiently Manage Time & 3.54 & .74 \\
\hline Promote Cultural Awareness/Diversity & 3.54 & .79 \\
\hline Engage in Critical Thinking & 3.54 & .78 \\
\hline Demonstrate Creative Thinking & 3.53 & .85 \\
\hline Handle Emotions & 3.52 & .67 \\
\hline Show Courage & 3.49 & .75 \\
\hline Develop Managerial Skills & 3.48 & .77 \\
\hline Effectively Lead a Team & 3.48 & .73 \\
\hline Create Stability & 3.47 & .71 \\
\hline Recognize Volunteers & 3.44 & .82 \\
\hline Assess Community Needs & 3.44 & .85 \\
\hline Identify Talent & 3.41 & .81 \\
\hline Evaluate People & 3.40 & .81 \\
\hline Delegate Tasks & 3.38 & .83 \\
\hline Create Vision & 3.38 & .88 \\
\hline Negotiate & 3.37 & .78 \\
\hline Handle Criticism & 3.35 & .66 \\
\hline Serve as a Coach & 3.33 & .74 \\
\hline Resolve Conflict & 3.32 & .71 \\
\hline Develop Volunteers & 3.28 & .80 \\
\hline Recruit Volunteers & 3.26 & .83 \\
\hline Train Volunteers & 3.23 & .83 \\
\hline Manage Volunteers & 3.22 & .80 \\
\hline Plan Strategically & 3.20 & .76 \\
\hline
\end{tabular}

Note. Scale: $1=$ No Knowledge, $2=$ Below Average, $3=$ Average Knowledge, 4=Above Average, $5=$ Exceptional Knowledge. 
Training needs are represented by the Mean Weighted Discrepancy Score (MWDS) (Borich, 1980). According to Table 4, the five highest rated training needs were resolve conflict, efficiently manage time, assess community needs, effectively lead a team, and prioritize tasks. The five lowest rated training needs were show empathy, display enthusiasm, show courage, exhibit a sense of humor, and reading skills.

Table 4.

Training Needs of Extension Agents

\begin{tabular}{|c|c|}
\hline Statement & MWDS $^{\mathrm{a}}$ \\
\hline Resolve Conflict & 5.49 \\
\hline Efficiently Manage Time & 4.38 \\
\hline Assess Community Needs & 4.29 \\
\hline Effectively Lead a Team & 4.02 \\
\hline Prioritize Tasks & 3.70 \\
\hline Delegate Tasks & 3.60 \\
\hline Build Relationships with Community & 3.58 \\
\hline Handle Criticism & 3.48 \\
\hline Recruit Volunteers & 3.36 \\
\hline Develop Managerial Skills & 3.33 \\
\hline Manage Volunteers & 3.32 \\
\hline Develop Volunteers & 3.32 \\
\hline Handle Emotions & 3.19 \\
\hline Create Vision & 3.11 \\
\hline Train Volunteers & 2.96 \\
\hline Employ Listening Skills & 2.89 \\
\hline Create Stability & 2.84 \\
\hline Recognize Volunteers & 2.82 \\
\hline Set Goals & 2.80 \\
\hline Demonstrate Creative Thinking & 2.75 \\
\hline Achieve Goals & 2.67 \\
\hline Employ Problem Solving Skills & 2.64 \\
\hline Communicate through Public Speaking & 2.60 \\
\hline Plan Strategically & 2.58 \\
\hline Exhibit a Positive Attitude & 2.51 \\
\hline Evaluate People & 2.47 \\
\hline Effectively Contribute to the Team & 2.40 \\
\hline Model Integrity & 2.39 \\
\hline Demonstrate Appropriate Behavior & 2.37 \\
\hline Exhibit Accountability & 2.31 \\
\hline Openness to Organizational Change & 2.30 \\
\hline Identify Talent & 2.21 \\
\hline Engage in Critical Thinking & 2.18 \\
\hline
\end{tabular}


Produce professional written documents

Exhibit Honesty

Promote Cultural Awareness / Diversity

Model Respectful Behavior

Build Relationships with Peers

Desire to Learn New Knowledge

Serve as a Coach

Serve as a Mentor

Negotiate

Show Empathy

Display Enthusiasm

Show Courage

Exhibit a Sense of Humor

Notes. ${ }^{a}$ Mean Weighted Discrepancy Score.

Lastly, the researchers determined the training needs by roles using the MWDS. According to Table 5, the only common training need by all three roles was resolve conflict. One training need for FCS not mentioned by the other roles was create vision. The 4-H role needs were handle emotions and handle criticism. The other two roles did not have a high need for those two skills.

Table 5.

Training Needs of Extension Agents by Roles

\begin{tabular}{llcc}
\hline Characteristics & & $N$ & $M W D S$ \\
\hline ANR $^{\mathrm{a}}$ & Resolve Conflict & 24.00 & 5.06 \\
& Efficiently Manage Time & 24.00 & 4.51 \\
& Prioritize Tasks & 24.00 & 4.23 \\
& Delegate Tasks & 24.00 & 3.58 \\
& Effectively Lead a Team & 24.00 & 3.40 \\
& Assess Community Needs & 24.00 & 3.40 \\
FCS $^{\mathrm{b}}$ & Effectively Lead a Team & & \\
& Build Relationships with Community & 17.00 & 4.59 \\
& Delegate Tasks & 17.00 & 3.78 \\
& Resolve Conflict & 17.00 & 3.74 \\
& Create Vision & 17.00 & 3.58 \\
$4-\mathrm{H}^{\mathrm{c}}$ & & & 3.34 \\
& Resolve Conflict & 28.00 & 6.96 \\
& Assess Community Needs & 28.00 & 5.55 \\
& Efficiently Manage Time & 28.00 & 5.43 \\
& Handle Emotions & 28.00 & 5.22 \\
& Handle Criticism & 28.00 & 4.98 \\
\hline
\end{tabular}

Notes. ${ }^{a}$ Agriculture and Natural Resources. ${ }^{b}$ Family and Consumer Sciences. ${ }^{c} 4-\mathrm{H}$. 


\section{Conclusions}

The participants randomly selected for this study were primarily female with a larger representation of 4-H agents. In addition, nearly half of the participants had over 16 years of experience. The participants perceived all of the leadership skills presented as important. The participants perceived their knowledge for all leadership skills to be average or greater, with the highest knowledge in the areas of exhibit honesty, demonstrate appropriate behavior, model integrity, model respectful behavior, and exhibit positive attitude. The participants perceived their knowledge of develop volunteers, recruit volunteers, train volunteers, manage volunteers, and plan strategically to be average.

Based on the findings of this study, the most important training needs were resolve conflict, efficiently manage time, assess community needs, effectively lead a team, and prioritize tasks. As stated earlier, research examining the leadership needs of Extension agents is nonexistent; hence, there are no prior studies to compare. However, the aforementioned skills do align with Katz's (1955) model and could be considered either human skills or conceptual skills. When the data were further examined to determine training needs by roles, only resolve conflict was indicated by all three roles. There were training needs identified which did not make the top five lists - for FCS, the agents perceived training needs in building relationship with community and create vision; for 4-H agents, perceived training needs were in handle emotions and handle criticisms.

\section{Implications and Recommendations}

With the possibility of declining or stagnant budgets, Extension organizations are looking for ways to compensate monetary shortfalls (McClure, Fuhrman, \& Morgan, 2012). Conducting professional development activities to increase efficiency or impart skills to be shared with stakeholders is crucial. The following implications and recommendations are specific to the context of the research in Tennessee, but other Extension organizations may benefit as well.

The results indicated that all 47 of the leadership skills presented in this study were important to Extension agents; furthermore, certain leadership skills and knowledge of those skills were more important. These data will assist Extension administrators and specialists in Tennessee to develop the most appropriate and relevant professional development opportunities for Extension agents. Knowing what leadership skills the agents need and seek to further develop is vital to creating quality in-service in an efficient manner. With the tight budgets and high accountability/impact reporting/evaluation measures of the Cooperative Extension Service, more effective utilization of time, money, training materials/curricula, and other resources for the development and implementation of in-service trainings is necessary.

In addition, Bennett (1975) discussed how people might change their knowledge, attitudes, skills, and aspirations (KASA) as a result of Extension programming. Knowledge is the lowest form of evaluation; trainings must be developed to address not only knowledge of the skills but also attitudes, skills, and aspirations. Now that the researchers have a baseline for knowledge, further investigation is needed in the areas of Extension agents to perform leadership 
skills and the ability to educate others concerning leadership skills.

In conclusion, the results of this study provide a good starting point for creating and implementing leadership development in-service trainings for agents. However, the researchers recognize that this study is limited by having one sample of Extension agents in Tennessee; therefore replicating the study with Extension agents in other states within the southern region and states across the nation would be beneficial. In addition to replicating this quantitative study, the researchers suggest conducting qualitative studies that will examine the leadership needs, knowledge, and abilities of Extension agents. The qualitative studies could also provide greater insight into the context in which agents lead through extension and their relationship with the communities they seek to develop.

\section{References}

Andenoro, A. C., Allen, S. J., Haber-Curran, P., Jenkins, D. M., Sowcik, M., Dugan, J. P., \& Osteen, L. (2013). National Leadership Education research agenda 2013-2018: Providing strategic direction for the field of leadership education. Retrieved from Association of Leadership Educators website: http://leadershipeducators.org/ResearchAgenda.

Anderson, C. (2013, August 21). The increasing importance of leadership [Web log post]. Retrieved from http://communitybuilders.org/the-increasing-importance-of-leadership/

Bennett, C. (1975). Up the hierarchy. Journal of Extension [On-line], 13(2). Available at: http://www.joe.org/joe/1975march/75-2-a1.pdf

Borich, G. D. (1980). A needs assessment model for conducting follow-up studies. The Journal of Teacher Education, 31(3), 39-42. doi:10.1177/002248718003100310

Boyd, B. L. (2004). Extension agents as administrators of volunteers: Competencies needed for the future. Journal of Extension, 42(2). Retrieved fromhttp://www.joe.org/joe/ 2004april/a4.php

Cooper, A. \& Graham, D. (2001). Competencies needed to be successful county agents and county supervisors. Journal of Extension, 39(1). Retrieved from http://www.joe.org/joe/ 2001february/rb3.php

Dillman, D. A., Smyth, J. D., \& Christian, L. M. (2009). Internet, Mail, and Mixed-Mode Surveys: The Tailored Design Method (3rd ed.). Hoboken, NJ: Wiley and Sons.

Doerfert, D. L. (Ed.) (2011). National research agenda: American Association for Agricultural Education's research priority areas for 2011-2015. Lubbock, TX: Texas Tech University, Department of Agricultural Education and Communications. 
Gallaher Jr, A. \& Santopolo, F. (1967).Perspectives on agent roles. Journal of Cooperative Extension, 5(4), 223-230. Retrieved from http://www.joe.org/joe/1967winter/1967-4a3.pdf

George, J. D. (1968). Agents' views of extension's role. Journal of Cooperative Extension, 6(4), 236-241. Retrieved from http://www.joe.org/joe/1968winter/ 1968-4-a6.pdf

Gonzalez , I., Howell, D., \& Lindley, W. (1984) Professional competencies needed by extension agents in the Pennsylvania Cooperative Extension Service. Journal of the American Association of Teacher Educators in Agriculture, 25(2), 30-36. doi: 10.5032/jaatea.1984.02030

John F. Kennedy Presidential Library \& Museum. (n.d.). Historical resources. Remarks prepared for delivery at the trade mart in Dallas. Retrieved from http://www.jfklibrary. org/Historical+Resources/Archives/Reference+Desk/Speeches/JFK/ 003POF03TradeMart11221963.htm

Katz, R. L. (1955). Skills of an effective administrator. Harvard Business Review, 33(1), 33-42.

Lakai, D. (2010). Identification of competencies needed by the Extension agents in North Carolina Cooperative Extension (Master's thesis). Available from: http://repository. lib.ncsu.edu/ir/bitstream/1840.16/6495/1/etd.pdf

Lindner, J. R., Murphy, T. H., \& Briers, G. E. (2001). Handling nonresponse in social science research. Journal of Agricultural Education, 42(4), 43-53. doi:10.5032/jae.2001.04043

McClure, M., Fuhrman, N., \& Morgan, A. (2012). Program evaluation competencies of extension professional: Implications for continuing professional development. Journal of Agricultural Education, 53(4), 85-97. doi:10.5032/jae.2012.04085

McKim, B., Lawver, R., Enns, K., Smith, A., \& Aschenbrener, M. (2013). Developing metrics for effective teaching in Extension Education: A multi-state factor-analytic and psychometric analysis of effective teaching. Journal of Agricultural Education, 54(2), 143-158. doi:10.5032/jae.2013.02143

Moore, L., \& Rudd, R. (2004). Leadership skills and competencies for Extension state directors and administrators. Journal of Agricultural Education, 45(3), 22-33. doi: 10.5032/jae.2004.03022

Moore, L. \& Rudd, R. (2005). Extension leaders' self-evaluation of leadership skill areas. Journal of Agricultural Education, 46(1), 68-78. doi:10.5032/jae.2005.01068

Patton, D., \& Blaine, T. (2001). Public issues education: Exploring Extension's role. Journalof Extension, 39(4). Retrieved from http://www.joe.org/joe/2001august/a2.php 
Robinson, R. (1964). Examining the role of agents in 4-H. Journal of Cooperative Extension, 2(2), 105-112. Retrieved from http://www.joe.org/joe/1964summer/1964-2-a6.pdf

Townsend, C. (1999). Educating leaders: Teachers for the next generation. The Agricultural Education Magazine, 72(1), 4-5

Trent, S., \& Donohue, T. (1971). Counseling: Another dimension in the agent's role. Journal of Cooperative Extension, 9(4), 20-22. Retrieved from http://www.joe.org/joe/1971winter/ 1971-4-a2.pdf

Woodrum, W., \& Safrit, R. (2003). Leadership practices of West Virginia University Extension Agents working with the 4-H youth development program. Journal of Extension, 41(3). Retrieved from http://www.joe.org/joe/2003june/rb3.php

\section{Author Biographies}

John L. Hall, $\mathrm{PhD}$, is an Assistant Professor of Agricultural Education and Leadership at Tennessee State University (TSU). John serves as an Extension Leadership Specialists for Tennessee Cooperative Extension. He teaches education and leadership courses; his research focus is on leadership competencies, styles, and development of individuals and teams. Jhall33@tnstate.edu

Thomas W. Broyles, $\mathrm{PhD}$, is an Associate Professor of Agricultural Education and Leadership at Tennessee State University (TSU). Thomas serves as the 4-H State Program Leader for Tennessee Cooperative Extension. He teaches education and leadership courses; his research focus is on problem solving and decision-making. Tbroyle1@tnstate.edu 